ORIGINAL ARTICLE

\title{
Deprivation, smoking, and quality of life in asthma
}

\author{
J B Austin, S Selvaraj, D Godden, G Russell
}

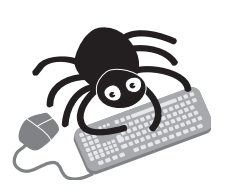

Additional tables are available on the Archives of Disease in Childhood website (www.archdischild.com/ supplemental)

See end of article for authors' affiliations .....................

Correspondence to: Dr J B Austin, Highland and Islands Health Research Institute, University of Aberdeen, The Green House, Inverness IV2 3ED, UK; jane.austin@hpct.scot. nhs.uk

Accepted 21 August 2004
Aims: To explore associations of deprivation and smoking, with prevalence of asthma, wheeze, and quality of life.

Methods: Survey, using International Study of Asthma and Allergies in Childhood (ISAAC) methodology, of children aged 13-14 years attending Scottish schools previously surveyed in 1995.

Results: $4665 / 5247$ (89\%) pupils completed questionnaires. 3656/4665 (78.4\%) had missed school for any reason in the last 12 months, $587(12.6 \%)$ because of asthma or wheeze. Compared to children with 1-3 wheeze attacks per year, those with $>12$ attacks in the last year were more likely to have missed school, twice as likely to have missed physical education in the last month, to report interference with home activities, or to have visited accident and emergency departments, and three times more likely to have been hospitalised. Deprivation was not independently associated with self-reported asthma or wheeze, but was associated with school absence, either for any reason or specifically for asthma or wheeze, but not with use of services such as accident and emergency visits, doctor visits, or hospital admissions. Active smoking was associated with wheezy symptoms, and active and passive smoking with use of medical services. These associations were independent of wheeze severity, treatment taken, and other associated atopic conditions. Smoking also had an impact on school absence and home and school activities.

Conclusions: Deprivation does not affect the prevalence of asthma or wheeze. Exposure to cigarette smoke was associated with the increased use of services. Deprivation and smoking have independent adverse effects on the quality of life in subjects with asthma or wheeze.
$\mathrm{T}$ he prevalence of asthma has increased in the western world in the last four decades ${ }^{12}$ but is now stabilising, ${ }^{3}$ or decreasing. ${ }^{4}$ There has been a downward trend in acute asthma episodes since 1993 in England and Wales, ${ }^{5}$ and results of serial prevalence surveys of adolescents show a decrease in reported wheeze in both England and Scotland. ${ }^{6}$ Despite most affected children having mild asthma, ${ }^{7}$ the social and economic impact on the family is significant. ${ }^{89}$ The child's quality of life can be profoundly affected by sleep disturbance, limitations in physical activity, and poor self-

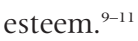

While studies from North America, ${ }^{12}$ Europe, ${ }^{13}$ and Scotland ${ }^{14}$ suggest that deprivation is associated with asthma, particularly if symptoms are severe, ${ }^{13}{ }^{14}$ a recent Scottish study showed no such effect, although the population studied was predominantly rural and relatively affluent. ${ }^{4}$ Erickson et al found that household income correlated positively with health related quality of life. ${ }^{15}$ Thus, the interrelations between environmental influences and disease are complex, and the recent International Study of Asthma and Allergies in Childhood (ISAAC) ${ }^{6}$ provided an opportunity to explore, at a national level, associations of deprivation and smoking with prevalence of wheeze, asthma, and quality of life.

\section{METHODS}

This study adopted the ISAAC protocol, including the selfcompleted questionnaire previously used in Scotland in 1995. ${ }^{76}$ The questionnaire included items on symptoms, diagnosis, and treatment of asthma, eczema, and hay fever. In order to assign deprivation ranks, pupils were asked for the first five digits of their postcode. Deprivation scores and ranks were derived from the Scottish Index of Multiple Deprivation (SIMD), ${ }^{17}$ which assigns a deprivation score and rank, based on a number of domains, to each ward, a ward being a small geographical area within local authority boundaries as defined by central government. For ease of interpretation we divided the ranks into quartiles, where 1 represents the most affluent group and 4 the most deprived group. Because for reasons of confidentiality we did not collect the last letter of the postcode, there were occasions when these spanned more than one ward; under these circumstances, a median rank was assigned. Additional questions concerning quality of life were also included, based on those used in a study of Croydon children ${ }^{19}$ and used in a previous study in the Highlands of Scotland. ${ }^{4}$

The sampling frame used in the 1995 prevalence study included mixed sex state secondary schools with over 100 pupils in each school year for every region, including Orkney, Shetland, and the Western Isles, together with the metropolitan areas of Edinburgh and Glasgow. One school from each region/island was selected randomly from the sampling frame. The same 14 schools that participated in 1995 were selected. All pupils in years 2 and 3 (aged 13-14) were invited to participate in the study. Information letters and consent slips were distributed to pupils by the schools prior to the fieldwork. Questionnaires were completed in the schools under the supervision of trained researchers between January and March 2002.

All data were double entered independently into an Access database. Data were analysed in accordance with ISAAC policy. ${ }^{16}$ We included "missing" or inapplicable responses in denominators for univariate analyses, but excluded them from subsequent bivariate analyses. SIMD ranks were

Abbreviations: ISAAC, International Study of Asthma and Allergies in Childhood; SIMD, Scottish Index of Multiple Deprivation 
Table 1 Diagnosis, symptoms, use of services, and quality of life factor (\%) by deprivation

\begin{tabular}{|c|c|c|c|c|c|}
\hline & \multicolumn{4}{|c|}{ Deprivation quartile } & \multirow[b]{2}{*}{ p value } \\
\hline & 1 & 2 & 3 & 4 & \\
\hline Diagnosis/symptoms & $n=1085$ & $n=1162$ & $\mathrm{n}=1054$ & $\mathrm{n}=997$ & \\
\hline Asthma reported & 23.6 & 25.0 & 24.8 & 25.1 & 0.635 \\
\hline Eczema reported & 26.3 & 29.3 & 24.1 & 19.6 & 0.008 \\
\hline Hay fever reported & 34.3 & 34.5 & 33.3 & 34.4 & 0.928 \\
\hline Wheeze in last 12 months & 26.1 & 26.8 & 31.1 & 27.1 & 0.406 \\
\hline Intermittent itchy flexural rash in last 12 months & 11.6 & 13.2 & 11.8 & 11.2 & 0.734 \\
\hline Rhinoconjunctivitis in last 12 months & 15.5 & 13.0 & 15.9 & 17.3 & 0.220 \\
\hline Sleep disturbance & 1.9 & 3.1 & 4.8 & 4.4 & 0.004 \\
\hline Speech limitation & 5.6 & 6.0 & 7.3 & 7.9 & 0.072 \\
\hline Severe wheeze (4+ attacks) & 7.0 & 6.2 & 6.4 & 5.5 & 0.321 \\
\hline Treatment in last 12 months for wheeze/asthma & 18.2 & 18.5 & 19.7 & 19.7 & 0.286 \\
\hline Use of services in last 12 months* & $n=509$ & $n=566$ & $n=543$ & $n=471$ & \\
\hline Doctor visit & 7.7 & 9.4 & 11.8 & 13.0 & 0.007 \\
\hline Hospital admissions & 5.7 & 4.6 & 8.1 & 7.0 & 0.090 \\
\hline Visit to $A \& E$ & 6.9 & 7.1 & 10.9 & 10.8 & 0.011 \\
\hline \multicolumn{6}{|l|}{ Impact on activity* } \\
\hline \multirow{5}{*}{$\begin{array}{l}\text { Missed school for any reason in last } 12 \text { months } \\
\text { Missed school because of asthma and wheeze in } \\
\text { last } 12 \text { months } \\
\text { Interfered ever with PE } \\
\text { Interfered with home activities }\end{array}$} & 79.2 & 83.0 & 85.8 & 86.4 & \multirow{3}{*}{$\begin{array}{l}0.003 \\
0.001\end{array}$} \\
\hline & & & & & \\
\hline & 18.9 & 23.3 & 23.4 & 30.8 & \\
\hline & 30.3 & 31.4 & 33.7 & 32.9 & 0.140 \\
\hline & 7.1 & 7.8 & 10.1 & 7.6 & 0.312 \\
\hline
\end{tabular}

divided into four categories for analysis purposes based on quartiles of population SIMD ranks. We performed Student's $t$ test to examine the linear trend of prevalence of symptoms, use of services, and quality of life factors across deprivation quartiles. Logistic regression analysis was used to assess the effect of deprivation on severity of wheeze and quality of life factors, simultaneously adjusting for smoking status, gender, and co-morbid conditions. Factors significant at univariate analysis with $\mathrm{p}$ values below 0.2 were considered in the multiple logistic regression analysis. Results are presented as percentages and odds ratios with $95 \%$ confidence intervals (CI). Since cluster sampling had a significant impact on the results, all the statistical analyses took into account of the additional variance arising from this study design. Probability values below 0.05 were considered as statistically significant. Stata version 8.0 was used for all analyses.

The study was approved by Multicentre Research Ethics Committee, and by relevant local research ethics committees. Participation was entirely voluntary.

\section{RESULTS}

All 14 (100\%) schools participated, and 4665/ 5247 (89\%) pupils completed questionnaires. Response rates by school varied from $83 \%$ to $94 \%$. Subjects were aged between 12 and 15 years, the majority (95.6\%) being aged 13-14 years; 2291 $(49.1 \%)$ were male; and $103(2.2 \%)$ were born outside the UK. Postcode information was complete for 4104 (88\%) cases. A further 194 (4\%) cases were assigned SIMD ranks if at least the first part of the postcode information was complete. Postcode information in the remaining $8 \%$ of questionnaires was either missing or insufficient to calculate deprivation ranks. The distribution of SIMD ranks among our sample was comparable to that of the Scottish population. ${ }^{17} 18$

Asthma was reported by 1141 (24.5\%) subjects and wheeze in the last 12 months by $1295(27.8 \%)$. The majority of subjects experiencing wheeze reported 1-3 attacks in the last 12 months.

A total of $3656 / 4665(78.4 \%)$ had missed school for any reason in the last 12 months, of whom 587 (12.6\%) missed

\begin{tabular}{|c|c|c|c|c|}
\hline \multirow[b]{2}{*}{ SIMD } & \multicolumn{2}{|c|}{ Reported asthma } & \multicolumn{2}{|c|}{ Current wheeze } \\
\hline & & & & \\
\hline Q1 & - & - & 1.00 & \\
\hline Q2 & - & - & 1.12 & $(0.86$ to 1.48$)$ \\
\hline Q3 & - & - & 1.29 & $(1.05$ to 1.58$)$ \\
\hline Q4 & - & - & 1.01 & $(0.75$ to 1.35$)$ \\
\hline \multicolumn{5}{|l|}{ Active smoking } \\
\hline Never smoker & 1.00 & - & 1.00 & - \\
\hline Ex-smoker & 1.05 & $(0.90$ to 1.22$)$ & 1.42 & (1.17 to 1.72$)$ \\
\hline Current & 0.83 & $(0.68$ to 1.01$)$ & 2.94 & (1.62 to 2.32$)$ \\
\hline \multicolumn{5}{|l|}{ Gender } \\
\hline Male & 1.00 & - & - & - \\
\hline Female & 0.80 & $(0.69$ to 0.93$)$ & - & - \\
\hline \multicolumn{5}{|l|}{ Hay fever } \\
\hline No & 1.00 & - & 1.00 & - \\
\hline Yes & 1.68 & (1.51 to 1.87$)$ & 2.66 & (2.27 to 3.12$)$ \\
\hline
\end{tabular}


school because of asthma or wheeze. Of the 2262 subjects reporting lifetime wheeze or asthma, 744 (32.9\%) reported interference with physical education (PE) and 186 (8.2\%) reported interference with home activities. A total of 240 $(10.6 \%)$ had a required a doctor visit, 208 (9.2\%) had attended an accident and emergency department (A\&E), and $148(6.5 \%)$ had had hospital admissions in the last 12 months.

Subjects with more frequent wheeze reported a greater impact on their quality of life. Compared to children with 1-3 attacks of wheeze in the last 12 months, those reporting more than 12 attacks were likely to miss school more often and for longer, were twice as likely to have missed PE in the last month, to report interference with home activities, or to have visited A\&E, and three times more likely to have been admitted to hospital (full data are provided in table A which is available on the $A D C$ website).

There was no association between deprivation and selfreported asthma or hay fever, though eczema was commoner in children from more affluent areas (table 1). With the exception of sleep disturbance, no associations between deprivation and measures of severity, such as speech limitation or frequency of attacks of wheeze were noted. Subjects in deprived areas reported greater use of services and impact on activities, and this was statistically significant for doctor visits, attending A\&E departments, and missing school.

Associations between a range of factors and diagnosis, symptoms, use of medical services, and impact on activities were explored in multiple logistic regressions analyses. Table 2 shows associations with diagnosis and symptoms. Self-reported asthma was associated with symptoms of hay fever, but not with active or passive smoking. Females were less likely to report asthma. In contrast, current wheeze was associated with previous or current smoking, and with symptoms of hay fever.

Table 3 shows associations with use of services. Visits to the doctor were associated with current smoking, passive smoke exposure, severity of wheeze, and treatment. Hospital admissions were associated with wheeze severity and treatment, while visits to A\&E were associated with current smoking, wheeze severity, and treatment. Deprivation was no longer associated with use of services when adjusted for smoking, wheeze severity, and treatment.
School absence for any reason was associated with deprivation, previous smoking, passive smoking, wheeze severity, treatment, and female gender. School absence for asthma/wheeze showed similar associations, except that the association with smoking by the individual was not significant, while that with concurrent hay fever was significant. Interference with PE was associated with current smoking, wheeze severity, treatment, female gender, eczema, and hay fever, while interference with home activities was associated with passive smoking, severity, treatment, female gender and hay fever (full data are provided in table B which is available on the $A D C$ website).

\section{DISCUSSION}

This representative national sample of young Scottish teenagers was part of an international survey using ISAAC methodology, which has been used extensively worldwide. ${ }^{20}$ The additional quality of life questions were based on those used by Anderson and colleagues. ${ }^{19}$ The questionnaire used is considered to be a reliable instrument for determining asthma symptoms in the last 12 months. ${ }^{21}$

Deprivation was not independently associated with selfreported asthma or wheezy symptoms, but was associated with school absence for any reason or specifically for asthma or wheeze. Active smoking was associated with wheezy symptoms, while active and passive smoking had significant associations with use of medical services, independent of wheeze severity, treatment taken, and other atopic problems.

Since older indices may not reflect rural deprivation adequately, we used the SIMD, a new index thought to have advantages for studies that incorporate both urban and rural settings. It is expressed as a continuous variable, but for this analysis, we expressed the data in quartiles, which provide sufficient sample sizes for robust statistical analysis and ease of interpretation of results.

In keeping with the general literature, the majority of wheezy subjects reported only mild to moderate symptoms. ${ }^{714}$ However, the impact on use of services and activities was significant. The number of children missing school or requiring doctor visits was comparable to those found in the Highlands ${ }^{4}$ but more children required more than two visits $(3.5 \% \vee 1.7 \%)$, had been admitted to hospital in the last year $(6.5 \% \vee 0.9 \%)$, and had attended accident and emergency departments, $(9.2 \% \quad v 3.4 \%)$. This may reflect differing

Table 3 Factors associated with use of services; findings from multiple logistic regression

\begin{tabular}{|c|c|c|c|c|c|c|}
\hline & \multicolumn{2}{|c|}{$\begin{array}{l}\text { Doctor visit in last } \\
12 \text { months }\end{array}$} & \multicolumn{2}{|c|}{$\begin{array}{l}\text { Hospital admission in } \\
\text { last } 12 \text { months }\end{array}$} & \multicolumn{2}{|c|}{$\begin{array}{l}\text { Visit to A\&E in last } \\
12 \text { months }\end{array}$} \\
\hline \multicolumn{7}{|l|}{ Active smoking } \\
\hline Never smoker & 1.00 & - & - & - & 1.00 & - \\
\hline Ex-smoker & 1.14 & (0.82 to 1.57 ) & - & - & 0.97 & (0.65 to 1.43$)$ \\
\hline Current & 2.09 & (1.43 to 3.04$)$ & - & - & 1.50 & (1.09 to 2.07 ) \\
\hline \multicolumn{7}{|l|}{ Passive smoking } \\
\hline None in the family & 1.00 & - & 1.00 & - & 1.00 & - \\
\hline Mother only & 1.31 & (0.74 to 2.30$)$ & 1.08 & (0.61 to 1.90$)$ & 1.60 & (0.93 to 2.75$)$ \\
\hline Father only & 1.63 & (1.10 to 2.40$)$ & 1.23 & $(0.72$ to 2.11$)$ & 1.50 & (0.95 to 2.37$)$ \\
\hline Parents & 1.48 & (1.00 to 2.18 ) & 1.33 & $(0.71$ to 2.51$)$ & 1.08 & $(0.65$ to 1.78$)$ \\
\hline Other & 2.09 & (1.03 to 4.25$)$ & 2.16 & $(0.79$ to 5.95$)$ & 1.81 & (0.68 to 4.83 ) \\
\hline \multicolumn{7}{|l|}{ Wheeze severity } \\
\hline None & 1.00 & - & 1.00 & - & 1.00 & - \\
\hline $1-3$ attacks & 2.03 & (1.34 to 3.06$)$ & 1.89 & (1.22 to 2.94$)$ & 1.97 & (1.37 to 2.83 ) \\
\hline 4 or more attacks & 3.26 & (2.05 to 5.19 ) & 2.90 & (1.99 to 4.23 ) & 3.20 & (2.15 to 4.77 ) \\
\hline \multicolumn{7}{|l|}{ Treatment taken } \\
\hline Yes & 3.21 & (2.28 to 4.50$)$ & 4.95 & $(3.10$ to 7.90$)$ & 2.92 & (2.12 to 4.01$)$ \\
\hline No & 1.00 & - & 1.00 & - & 1.00 & - \\
\hline \multicolumn{7}{|c|}{$\begin{array}{l}\text { Data are odds ratios }(95 \% \mathrm{CI}) \text {. } \\
\text { Associations are significant when } \mathrm{Cl} \text { does not include } 1 \text {. } \\
\text { - indicates that the factor did not reach significance for inclusion in the final model. } \\
\text { Not shown in the table are SIMD, gender, hay fever, and eczema, which were included but not significant in the } \\
\text { final model. }\end{array}$} \\
\hline
\end{tabular}




\section{What is already known on this topic}

- Asthma may be associated with school absence and limited physical activity

- There is conflicting literature on the association of deprivation and asthma

- Deprivation has been associated with poorer treatment and more hospital admissions

distances between home and hospital, a view supported by an American study which found that the supply and character of medical care was an important influence on the likelihood of paediatric admissions. ${ }^{23}$

Asthma and wheeze, including frequent wheeze, were not associated with deprivation expressed as SIMD. This contrasts with studies from North America, but is consistent with Strachan and colleagues' UK study. ${ }^{12}{ }^{24}$ Previous studies from Europe and the UK have shown an association between deprivation and severe wheeze, a finding not replicated here. ${ }^{1325}$ The large UK study by Duran-Tauleria and Rona ${ }^{25}$ found a lower parent reported prevalence of asthma and wheeze compared with Scottish studies. ${ }^{26}$ These authors suggested that variations in deprivation largely account for these regional differences, perhaps due to differences in management. ${ }^{25}$ However, they used a deprivation index that is considered to have an urban bias. We found no difference in reported treatment related to deprivation.

The age at which children are studied may be important. A study of younger primary school children showed a relation between asthma and deprivation, independent of parental smoking. ${ }^{27}$ However, among our adolescent study population, there was no association with deprivation. In studies of young people in the West of Scotland, there was relatively little health inequality in adolescence for chronic illness including asthma, other than for severe chronic illness determined from infancy. ${ }^{28}$ These authors suggest that, in adolescence, "influences associated with the secondary school, the peer group and youth culture cut across influences associated with home background or neighborhood in such a way as to reduce or removes class differences in health". Class gradients may then reappear in adulthood.

In our study, the association between deprivation and school absence was statistically significant independent of treatment and wheeze severity and, although not statistically significant, children from more deprived areas did report a greater degree of interference with activities. Ernst et al, in a study of Canadian primary school children, found that children from the least advantaged homes were more likely to present with exercise induced bronchospasm. ${ }^{29}$ Our association of deprivation with school absence was consistent with a study of schoolchildren in Tayside. ${ }^{30}$ We also observed that interference with school or home activities was more likely in those who had hay fever and eczema-that is, in more atopic subjects.

Exposure to cigarette smoke also had a significant impact on current wheeze, use of services, and interference with activity. Among adolescents, smoke exposure is a more important factor than deprivation in relation to symptoms, use of services, and impact on activities. These findings are consistent with other literature. A study of young people aged 13-18 years showed that subjects who smoke, especially girls, report a higher prevalence of respiratory symptoms than nonsmokers. ${ }^{31}$ Smoking also influences hospital admissions in children aged between 3 and 15 years. ${ }^{32}$ Within the UK, Burr et al reported an association between deprivation and hospital

\section{What this study adds}

- This study used an index of deprivation that reflects rural, as well as urban deprivation

- Using this index, no association between deprivation and prevalence of asthma or wheeze, was found in this national study

- However, deprivation was associated with school absence, both due to asthma and wheeze and to other unspecified reasons

- Active smoking was associated with wheeze, while active and passive smoking were associated with use of medical services and school absence

- It might therefore be expected that reducing deprivation may not affect prevalence of asthma and wheeze in this age group, but may reduce their impact, while reducing smoking may lower prevalence of wheeze, use of services, and impact on activities

admissions not explained by variations in prevalence, but possibly associated with smoking. ${ }^{33}$

\section{Conclusion}

A significant number of children with wheeze encounter interference with school attendance, sleep, exercise and general activities, and require medical services. The majority report only mild or moderate wheeze, but service providers need to address the needs of subjects with more frequent symptoms who experience the greatest morbidity. In this age group, prevalence of asthma and wheeze are not directly associated with deprivation, therefore measures to ameliorate deprivation per se are unlikely to influence the burden of disease. However, deprivation is associated with school absence, and relieving deprivation may reduce the impact of disease. Both active smoking and passive exposure to smoke have major effects on symptoms, use of medical services, schooling, and other activities. Other associated atopic syndromes also have detrimental effects on symptoms and activities. These observations should inform the design and provision of health promotion and healthcare for this important group in society.

\section{ACKNOWLEDGEMENTS}

The study was funded by the Chief Scientist Office, Edinburgh. We wish to thank all the schools and pupils who took part, without whom the study could not have succeeded. We also thank Dr Sara Bradley, research manager; Gillian Goodman, Anne Fraser, and Mary Langridge who so diligently undertook the fieldwork; Kay Lackie for administrative support; and TK Manimekalai for statistical assistance.

\section{Authors' affiliations}

J B Austin, Department of Child Health, Raigmore Hospital, Inverness IV2 3UJ, Scotland, UK

S Selvaraj, D Godden, Highland and Islands Health Research Institute, University of Aberdeen, The Green House, Inverness IV2 3ED, Scotland, UK

G Russell, Department of Child Health, University of Aberdeen, Foresterhill, Aberdeen AB9 2ZD, Scotland, UK

Competing interests: none declared

\section{REFERENCES}

1 Woolcock AJ, Peat JK. Evidence for the increase in asthma worldwide. Ciba Found Symp 1997;206:122-39.

2 Omran $M$, Russell $G$. Continuing increase in respiratory symptoms and atopy in Aberdeen schoolchildren. BMJ 1996;312:34. 
3 Ronchetti R, Villa MP, Barreto $M$, et al. Is the increase in childhood asthma coming to an end? Findings from three surveys of schoolchildren in Rome, Italy. Eur Respir J 2001;17:881-6.

4 Austin JB, Selvaraj S, Russell G. Childhood asthma in the Highlands of Scotland-morbidity and school absence. Scott Med J 2004;49:18-21.

5 Sunderland RS, Fleming DM. Continuing decline in acute asthma episodes in the community. Arch Dis Child 2004;89:282-5.

6 Anderson HR, Ruggles R, Strachan DP, et al. Trends in prevalence of symptoms of asthma, hay fever, and eczema in 12-14 year olds in the British Isles, 1995-2002. BMJ 2004;328:1052-3.

7 Kaur B, Anderson HR, Austin J, et al. Prevalence of asthma symptoms, diagnosis, and treatment in 12-14 year old children across Great Britain (international study of asthma and allergies in childhood, ISAAC U.K). BMJ 1998;316:118-24.

8 von Mutius E. The burden of childhood asthma. Arch Dis Child 2000;82(suppl II):ii2-ii5.

9 Diette GB, Markson L, Skinner EA, et al. Nocturnal asthma in children affects school attendance, school performance, and parents' work attendance. Arch Pediatr Adolesc Med 2000;154:923-8.

10 Forrest CB, Starfield B, Riley AW, et al. The impact of asthma on the health status of adolescents. Pediatrics 1997;99:e11-22.

11 Price JF. Issues in adolescent asthma: what are the needs? Thorax 1996:51(suppl 1):S13-17.

12 Weitzman M, Gortmaker S, Sobol A. Racial, social, and environmental risks for childhood asthma. Am J Dis Child 1990; 144:1189-94.

13 Mielck A, Reitmeir P, Wist M. Severity of childhood asthma by socioeconomic status. Int J Epidemiol 1996;25:388-93.

14 Mitchell RG, Dawson B. Educational and social characteristics of children with asthma. Arch Dis Child 1973;48:467-71.

15 Erickson SR, Munzenberger PJ, Plante MJ, et al. Influence of sociodemographics on the health-related quality of life of pediatric patients with asthma and their caregivers. J Asthma 2002;39:107-17.

16 Ellwood P, Asher MI, Beasley R, et al. ISAAC (International study of asthma and allergies in childhood). Phase three manual. Auckland, New Zealand: ISAAC International Data Centre, 2000 (ISBN 0-473-06910-5).

17 Social Disadvantage Research Centre, Department of Social Policy and Social Work, University of Oxford. Scottish Indices of Deprivation 2003. Available from: http://www.scotland.gov.uk/library5/social/siod.pdf.

18 Social Disadvantage Research Centre, Department of Social Policy and Social Work, University of Oxford. Scottish Indices of Deprivation 2003. Available from http://www.scotland.gov/library5/social/soiddata.xls.
19 Anderson HR, Bailey PA, Cooper JS, et al. Morbidity and school absence caused by asthma and wheezing illness. Arch Dis Child 1983;58:777-84

20 The International Study of Asthma and Allergies in Childhood (ISAAC) Steering Committee. Worldwide variation in prevalence of symptoms of asthma, allergic rhinoconjunctivitis, and atopic eczema: ISAAC. Lancet 1998;351:1225-32.

21 Jenkins MA, Clarke JR, Carlin JB, et al. Validation of questionnaire and bronchial hyperresponsiveness against respiratory physician assessment in the diagnosis of asthma. Int J Epidemiol 1996;25:609-16.

22 Farmer JC, Baird AG, Iversen L. Rural deprivation: reflecting reality. Br J Gen Pract 2001;51:486-91.

23 Goodman DC, Fisher ES, Gittelsohn A, et al. Why are children hospitalized? The role of non-clinical factors in pediatric hospitalizations. Pediatrics 1994;93:896-902.

24 Strachan DP, Anderson HR. Limb ES, et al. A national survey of asthma prevalence, severity, and treatment in Great Britain. Arch Dis Child 1994;70:174-8.

25 Duran-Tauleria E, Rona RJ. Geographical and socioeconomic variation in the prevalence of asthma symptoms in English and Scottish children. Thorax 1999:54:476-81.

26 Austin JB, Russell G, Adam MG, et al. Prevalence of asthma and wheeze in the Highlands of Scotland. Arch Dis Child 1994;71:211-16.

27 Wassall H, Devenny A, Russell G, et al. The role of deprivation in childhood atopy in Aberdeen. A study over 10 years. Am J Respir Crit Care Med 2001;163:A719

28 West $\mathbf{P}$. Health inequalities in the early years: is there equalisation in youth? Soc Sci Med 1997:44:833-58.

29 Ernst P, Demissie K, Joseph L, et al. Socioeconomic status and indicators of asthma in children. Am J Respir Crit Care Med 1995;152:570-5.

30 McCowan C, Bryce FP, Neville RG, et al. School absence-a valid morbidity marker for asthma? Health Bull (Edinb) 1996:54:307-13.

31 Holmen TL, Barrett-Connor E, Clausen J, et al. Gender differences in the impact of adolescent smoking on lung function and respiratory symptoms. the Nord-Trondelag Health Study, Norway, 1995-1997. Respir Med 2002;96:796-804.

32 Gurkan F, Ece A, Haspolat K, et al. Predictors for multiple hospital admissions in children with asthma. Can Respir J 2000;7:163-6.

33 Burr ML, Verrall C, Kaur B. Social deprivation and asthma. Respir Med 1997:91:603-8.

\section{Committee on Publication Ethics Seminar 2005 Friday 11 March 2005, 9.30 am - 5 pm, BMA House, London}

This year's seminar will focus on COPE's new Code of Conduct for Editors and interactive workshops on common ethical and editorial dilemmas. The seminar is for editors, authors, and all those interested in increasing the standard of publication ethics.

The Code aims to set a new basic standard for the ethical conduct of editors and sets out guidelines for quality and correcting the record, standing by decisions made, ethics committee approval, consent for publication confidentiality of submitted material, guidance to authors, pursuing misconduct, relationship to publishers, owners, and advertisers, and conflict of interest. The code also creates a mechanism to refer a complaint to COPE if an editor has breached the code.

The seminar will include:

- The new Code of Conduct for Editors

- Dr lona Heath, Chair BMJ Ethics Committee-research, audit, and ethics committee approval

- COPE's new website-full text and keyword searching for COPE's advice on specific issues, for example research misconduct, conflict of interest, and deception

- Interactive workshops-common ethical and editorial dilemmas for editors

- Opportunities to network with other editors and share your experiences and challenges

The seminar is free for COPE members and $£ 30.00$ for non-members. Numbers are limited and early booking is advisable. For registrations or more information please contact Sam Knottenbelt at cope@bmigroup.com or call 0207383 6602. For more information on COPE see www.publicationethics.org.uk/ 